\title{
Visual Cortex Plasticity Following Peripheral Damage To The Visual System: fMRI Evidence
}

\author{
João Lemos ${ }^{1}$ • Daniela Pereira ${ }^{2,3}$ - Miguel Castelo-Branco ${ }^{3,4}$
}

Published online: 20 August 2016

(C) Springer Science+Business Media New York 2016

\begin{abstract}
Over the last two decades, functional magnetic resonance imaging (fMRI) has become a powerful research method to investigate cortical visual plasticity. Abnormal fMRI response patterns have been occasionally detected in the visually deprived cortex of patients with bilateral retinal diseases. Controversy remains whether these observations indicate structural reorganization of the visual cortex or unmasking of previously silent cortico-cortical connections. In optic nerve diseases, there is weak evidence showing that early visual cortex seems to lack reorganization, while higher-order visual areas undergo plastic changes which may contribute to optimise visual function. There is however accumulating imaging evidence demonstrating trans-synaptic degeneration of the visual cortex in patients with disease of the anterior visual pathways. This may preclude the use of restorative treatments in these patients.
\end{abstract}

This article is part of the Topical Collection on Neuro-Ophthalmology

João Lemos

merrin72@hotmail.com

Daniela Pereira

djp@sapo.pt

Miguel Castelo-Branco

mcbranco@ibili.uc.pt

1 Department of Neurology, Coimbra University Hospital Center, Praceta Mota Pinto, 3000-075 Coimbra, Portugal

2 Neuroradiology Department, Coimbra University Hospital Center, Coimbra, Portugal

3 Institute of Nuclear Sciences Applied to Health (ICNAS)/Institute for Biomedical Imaging and Life Sciences (CNC.IBILI),

Coimbra, Portugal

4 Faculty of Medicine, Coimbra University, Coimbra, Portugal
Here, we review and update the body of fMRI evidence on visual cortical plasticity.

Keywords Visual plasticity · Reorganization · Neuronal adaptation $\cdot$ Functional magnetic resonance imaging $\cdot$ Lesion projection zone $\cdot$ Intact projection zone $\cdot$ Preferred retinal location

\section{Introduction}

Cortical plasticity describes functional and structural expe rience-dependent changes in the cerebral cortex, including those occurring as part of the normal learning experience to improve cognitive and/or motor performance, as well as those taking place during recovery following injury of the peripheral or central nervous system [1]. Visual cortex plasticity following lesions of the visual pathways has been the focus of an extensive body of research over the last 50 years. Indeed, by determining the presence and extent of such changes, it then becomes possible to develop tailored rehabilitative and restorative interventions aiming to improve patients' visual outcome. In this review, we will use the term 'reorganization' to refer to long-term plastic structural changes within the underlying visual cortex in response to visual loss (e.g. axonal sprouting and subsequent cortical remapping) [2]. It should be noted however that some groups extend the use of this term to include the possibility of long-term functional changes (e.g. uncovering/re-weighting of signals mediated by pre-existing cortical connections between extrastriate and striate visual cortex; long-term potentiation and depression) [3, 4]. Others have called this latter phenomenon functional reorganization, as opposed to structural reorganization (for further details, see Wandell and Smirnakis 2009) [5, 6]. 'Adaptation', on the other hand, will be used here to denote short-term functional 

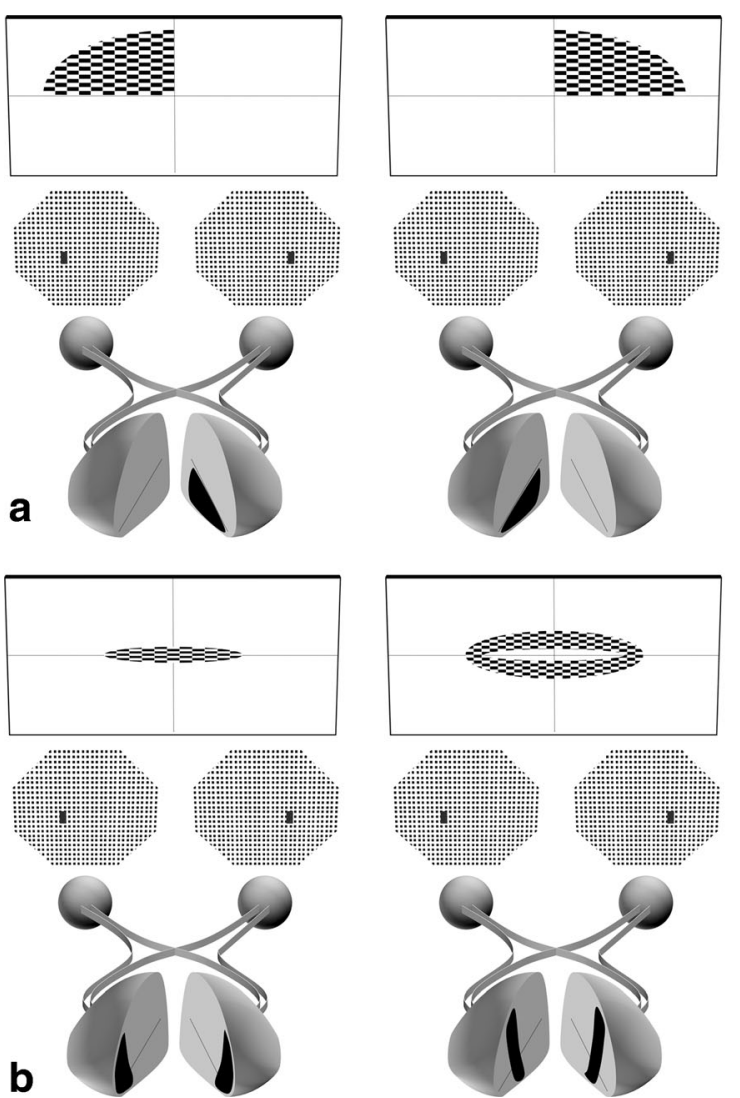

Fig. 1 Retinotopic mapping in polar coordinate space. During this procedure, a subject is presented with a contrast-reversing checkerboard pattern that progressively rotates around its apex (wedges - for visual angle mapping) (a) or expands (rings - for eccentricity mapping) (b) through regions of the visual field, eliciting a 'travelling wave' of blood oxygen level-dependent (BOLD) activity in the primary visual cortex (V1) [16-18]. For each of the eight panels, rectangular shapes with wedge or ring stimuli inside represent the visual paradigm, hexagonal

modifications of neuronal interactions within the visual cortex (e.g. adjustments to the neuronal responses) [7]. When deprived from its normal retinal input, visual cortex may also undergo degenerative changes, which imply progressive loss of neuronal structure and/or function, ultimately leading to neuronal death/cortical atrophy [8].

In this paper, we summarize and update the latest functional magnetic resonance imaging (fMRI) evidence on human visual cortical plasticity, giving special emphasis to studies which have investigated cortical intramodal plasticity (i.e. changes within the visual cortex, elicited by visual stimulation) following retinal and optic nerve lesions, whether acquired or congenital. In some congenital eye disorders (e.g. rod achromacy), it is fairly consensual that the primary visual cortex (V1) undergoes reorganization and remapping, highlighting its potential to reorganize at an early stage of development [9]. Thus, V1 regions chronically deprived of their normal visual input may still show blood oxygen leveldependent (BOLD) activity when adjacent areas surrounding the scotoma are visually stimulated [9]. In contrast, in eye

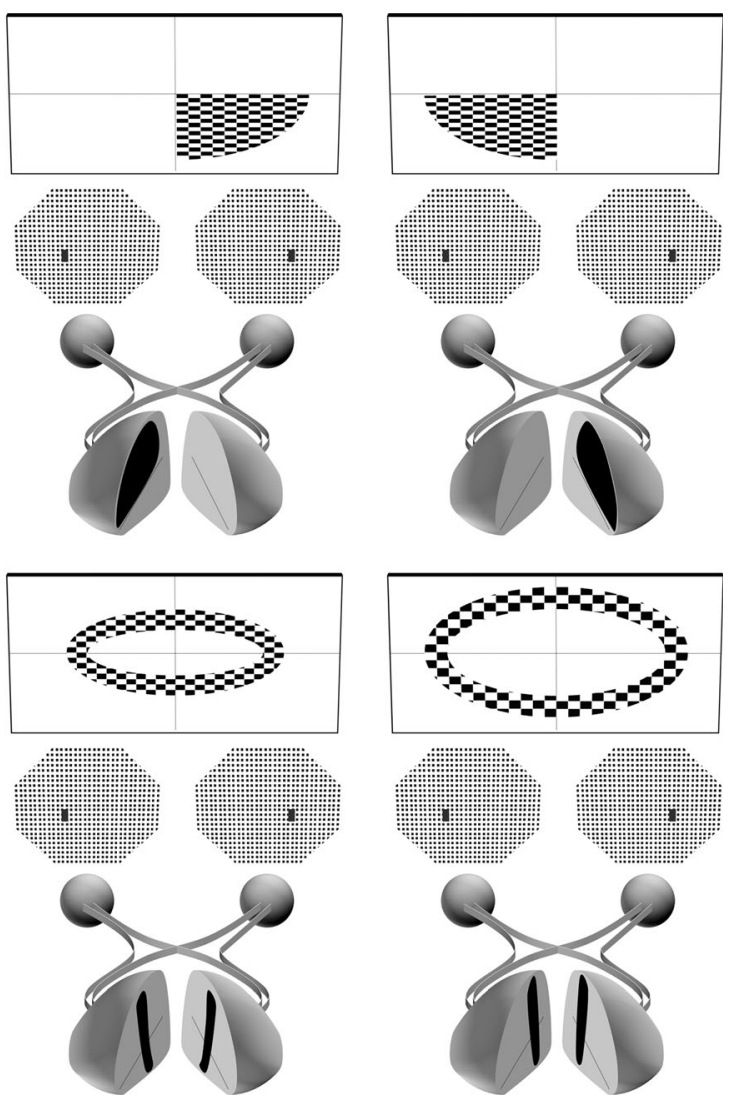

shapes depicted immediately below represent normal visual fields, and spheres (ocular globes) connected to semi-elliptical shapes (occipital lobe) far below represent the visual pathways. Inside each of the latter shapes (flattened representation of V1), BOLD activity is represented in black. Note that the central (foveal) portion of the visual field is represented at the posterior portion of V1 (occipital pole) while the peripheral visual field representation extends anteriorly (b)

diseases acquired later in life (e.g. macular degeneration), the cortex is less plastic, and reorganization does not seem to occur; thus, V1 visually deprived areas no longer respond to visual stimulation [10, 11]. In regards to adult V1 plasticity, however, anecdotal reports have claimed fMRI evidence for large-scale reorganization in V1, by demonstrating foveal V1 BOLD activity in visually deprived regions in patients with macular degeneration [3]. One reason that may have accounted for the above-mentioned finding is the methodology used. Specifically, while some groups have performed standard retinotopic mapping under passive viewing conditions (Figs. 1 and 2), others have used alternative visual paradigms requiring additional attentional resources (Fig. 4c), which by itself may have influenced the BOLD signal response $[3,9]$. Other factors that may explain discrepancies between fMRI studies on adult visual cortex plasticity include the clinical heterogeneity among patients and the intrinsic properties of the fMRI BOLD signals. Since a greater degree of cortical degeneration may render plasticity suboptimal, evaluating patients at different stages of the disease may play 
Fig. 2 Normal retinotopic mapping in polar coordinate space in an asymptomatic Leber's hereditary optic neuropathy (LHON) carrier (female, 43 years)

(a) and a control (female,

42 years) (b) participants [19].

Both showed normal central

(foveal) visual fields, and retinotopic mapping shows preservation of the retinotopic maps at the foveal confluence. Polar angle stimuli maps angular position regarding the centre of gaze that can be represented by a pseudocolour-coded map. $L H$ left hemisphere, $R H$ right hemisphere. Courtesy of Otília C. d' Almeida

\section{LHON carrier}
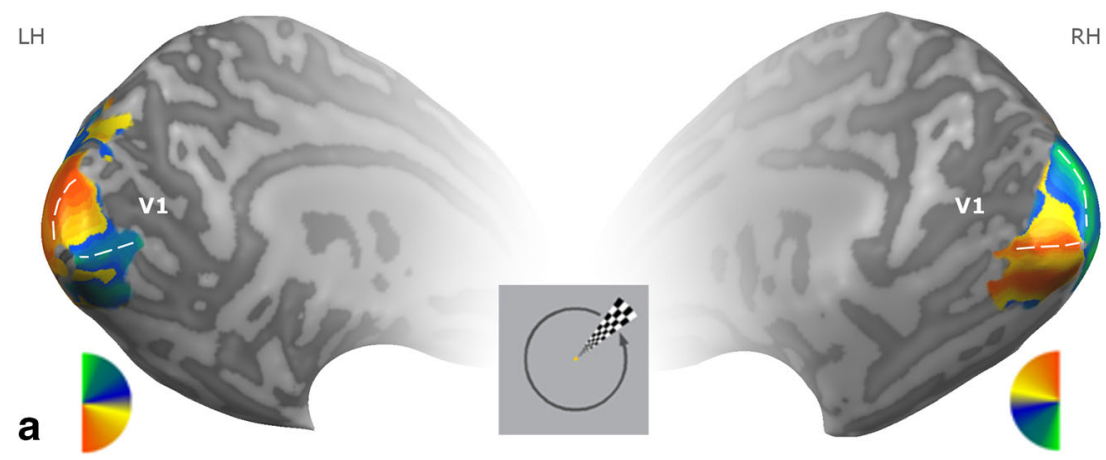

Control
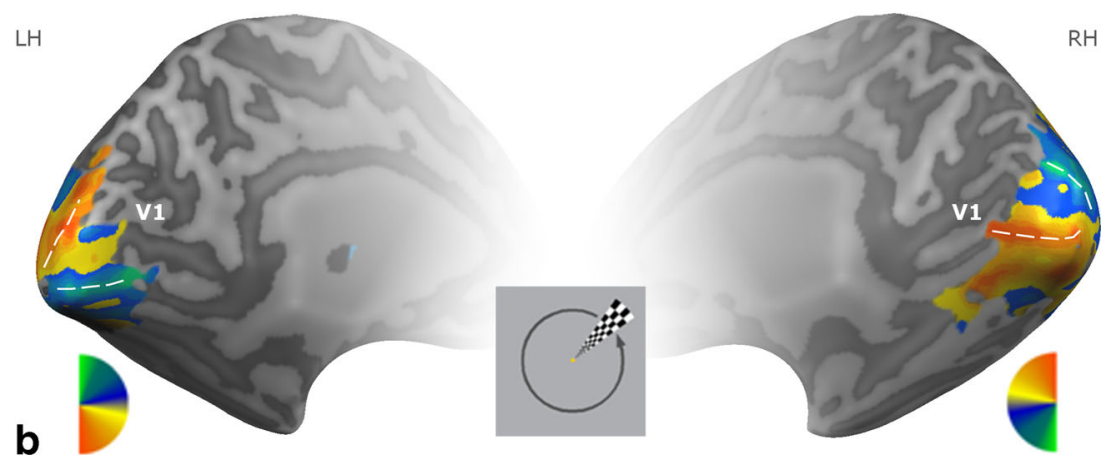

a role in the variability of BOLD signal modulation reported [8]. Also, some authors have argued that since the BOLD signal probably reflects synaptic input into $\mathrm{V} 1$ rather than spiking output, fMRI studies reporting absence of V1 activity may in fact not be detecting spiking activity in the context of synaptic reorganization [12]. Contrasting with fMRI studies on macular degeneration, the use of retinotopic mapping to investigate in detail V1 plasticity in other eye diseases such as glaucoma and optic neuritis has been scarce [13••, 14]. Nevertheless, several block-design experiments performed in patients with optic neuritis have shown that visual cortical plasticity probably extends beyond V1 in these diseases, highlighting the possible role of higher-order visual areas in maintaining visual function [15].

\section{Retinal Lesions}

Patients with congenital rod achromacy lack functioning cone photoreceptor cells, mostly concentrated in the central retina (fovea), resulting in permanent bilateral central scotomas. Thus, foveal projection areas located in posterior V1 become deafferented since birth (lesion projection zone (LPZ)) while more anterior $\mathrm{V} 1$ areas responding to visual peripheral stimuli receive normal retinal input (intact projection zone (IPZ)) (Fig. 3). Interestingly, Baseler et al. has found BOLD activity in foveal V1 in three rod achromats, but not in controls, during perifoveal visual stimulation (Fig. 4a). Strikingly, IPZ BOLD signal seemed to shift towards LPZ [9]. These findings provided first time fMRI evidence for V1 reorganization in patients with very early retinal damage in life, possibly through novel axonal projections, suggesting that the receptive fields of perifoveolar neurons surrounding LPZ had shifted towards V1 areas, deprived of foveolar signals. Alternatively, these findings could represent: (1) an abnormal developmental organization since birth (and not necessarily reorganization); (2) a functional imbalance between mutually inhibitory rod- and cone-driven signals in V1, which could have unmasked the rod-signal, resulting in perifoveal BOLD signal expansion; and (3) upstream reorganization (i.e. lateral geniculate nucleus (LGN) and/or retina) [6, 20, 30]. One question remained unanswered, regarding the discrepancy between the extent of V1 reorganization found in patients $(\sim 10 \mathrm{~mm})$ versus animals $(\sim 6 \mathrm{~mm})$ [31]. Since the lateral spread of horizontal axonal connections is the likely substrate for cortical reorganization in V1 after peripheral retinal lesions in animals, usually extending $\sim 6-8 \mathrm{~mm}$, the fMRI BOLD signal extending beyond this size in humans may indicate differences between species, the existence of a polysynaptic chain of horizontal connections in humans and/or size estimation differences between fRMI and single-cell recording methods [3, 12, 32-34].

The pioneering study of Baseler et al. has initiated a longstanding and still unsettled controversy on whether or not 

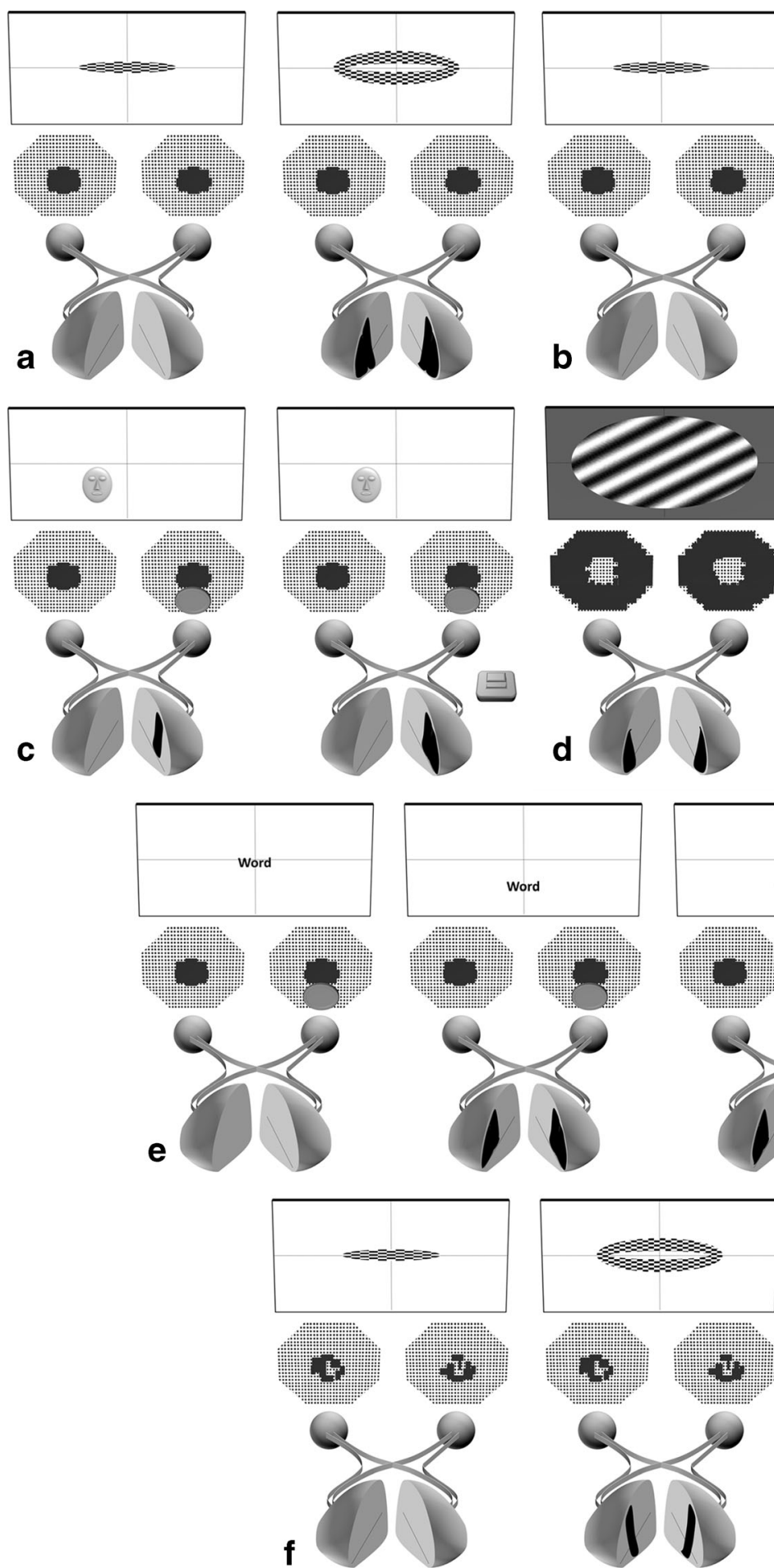

visual cortex has the potential to reorganize, especially in acquired retinal lesions (see Table 1). Indeed, following this study, Sunness et al. reported an absence of BOLD signal in V1 LPZ of an adult patient with acquired dry macular degeneration (MD) [11]. This supported the view that for individuals with retinal disease acquired later in life, V1 may have lost its potential to remap. This patient demonstrated
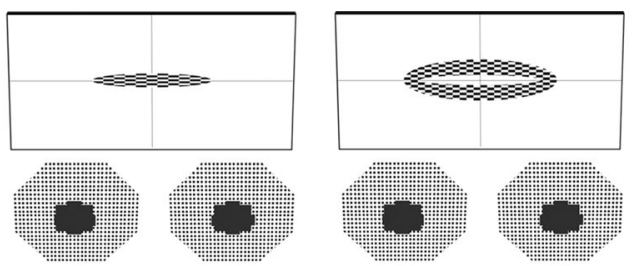

b
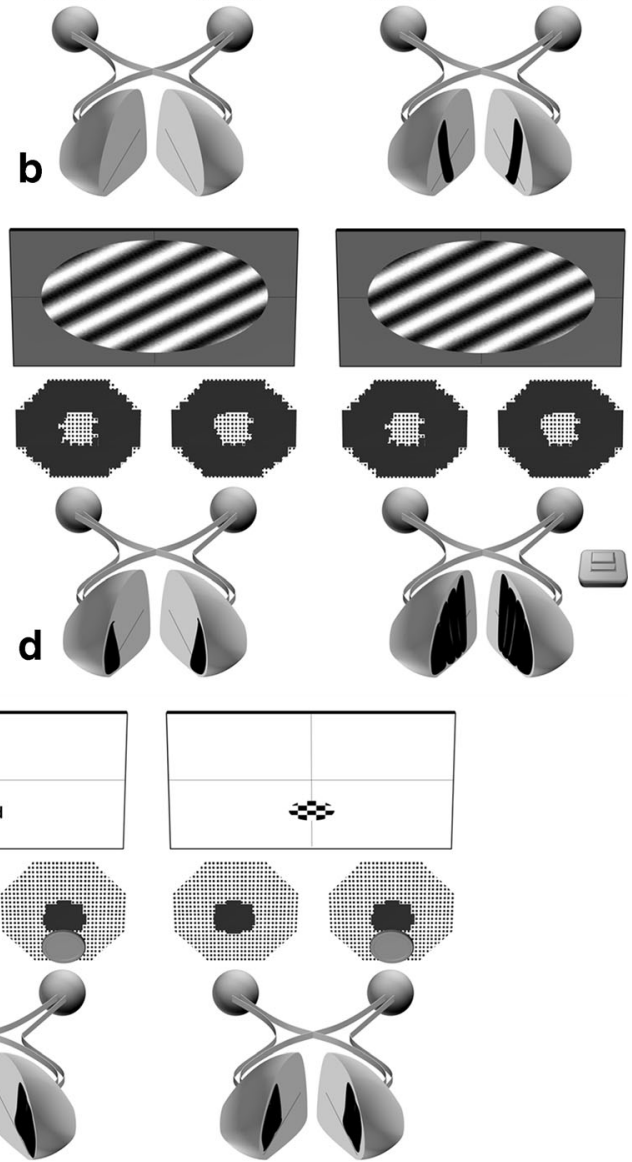

pericentral scotomas partially sparing foveal vision, which may have preclude a functional change in V1 LPZ (see below). Yet, Baker et al. provided contrasting results in two MD patients [3]. Here, the authors employed an fMRI task where subjects were required to view a series of visual stimuli (i.e. scenes, objects or faces) presented at the perifoveal border of their central scotoma. Stimuli were presented precisely in a 
4 Fig. 4 fMRI evidence for primary visual cortex (V1) plasticity following retinal lesions. a In congenital retinal diseases such as rod achromacy, foveal stimulation (left) does not activate foveal V1 due to the presence of bilateral central scotomas, whereas perifoveal stimulation (right) activates not only its corresponding retinotopic location but also the visually deprived foveal area (occipital pole) [9]. b Contrary to rod achromacy patients, in acquired retinal diseases such as macular degeneration, foveal stimulation (left) does not activate foveal V1, and perifoveal stimulation (right) only activates its corresponding retinotopic location in V1 [10]. Task design may influence BOLD activity in the visually deprived foveal area (occipital pole) in macular degeneration patients. $\mathbf{c}$ Whereas during passive viewing of stimuli presented perifoveally (left), activation is seen at the corresponding retinotopic V1 location, adding a complex task to the paradigm (e.g. one-back task) (right) elicits additional activation at the visually deprived foveal area (occipital pole) [24]. Similarly, in patients with retinitis pigmentosa, who characteristically demonstrate bilateral peripheral scotomas, task can also influence BOLD activity in the visually deprived areas (anterior V1 in this case). d Whereas during passive viewing of stimuli spanning $\sim 30^{\circ}$ diameter (left), activation is seen only at foveal area (occipital pole), adding a complex task to the paradigm (e.g. one-back task) (right) elicits additional activation at the visually deprived peripheral areas (anterior V1) [26]. Not all studies in macular degeneration have shown absence of $\mathrm{V} 1$ foveal activation under passive viewing. $\mathrm{e}$ Whereas foveal stimulation (left) does not activate foveal V1, perifoveal stimulation using visual words (centre) or checkerboards (right) activates both the corresponding retinotopic location and the visually deprived foveal area (occipital pole) [3, 21]. Foveal sparing seems to preclude the presence of $\mathrm{V} 1$ foveal activation during passive viewing of perifoveal stimuli in macular degeneration patients. f Foveal stimulation (left) does not activate foveal V1, and perifoveal stimulation (right) only activates its corresponding retinotopic location in V1 [11]. A pressing button depicted in $\mathbf{c}$ and $\mathbf{d}$ represents the one-back task (OBT). Examples in $\mathbf{c}$ and $\mathbf{e}$ depict fMRI paradigms under monocular stimulation, by covering one eye. For further details, see Fig. 1 legend

predefined area that lies in the intact peripheral part of their visual field where patients deprived of foveal vision often develop an alternative retinal locus to fixate - preferred retinal locus (PRL). They were further told to indicate whether the current visual stimulus had been presented immediately before (one-back task (OBT)). Notably, a robust BOLD response was found in the foveal confluence including V1 (LPZ) in patients but not in control subjects. In a parallel experiment, visual stimuli (i.e. words) were presented either to the fovea or to the PRL, but now without using OBT, to avoid the possible influence of task bias in BOLD signal. Still, it remarkably replicated the first experiment's findings (Fig. 4e) [3]. BOLD activity at the LPZ was thought to represent either disinhibition of pre-existing horizontal connections, axonal sprouting or feedback to V1 from higher visual areas [2, 37].

The authors' claim that their results were a demonstration of large-scale reorganization of V1 has generated criticisms mostly levelled at the experimental design, the pattern of V1 activity and the definition of reorganization used. Since the paradigm employed by Baker et al. (OBT) was more complex in nature than that usually used in conventional retinotopic mapping, this could have amplified the unmasking of previously silent feedback connections between higher-order visual areas and V1, especially in patients [25]. Additionally, if such connections are part of the normal circuitry of the visual cortex, some authors disagree that this represents reorganization, rather considering it a functional change without specific modifications in connection properties [6, 23••]. Also, in one of the patients, the pattern of LPZ activity thought to reflect reorganization was not consistent with the electrophysiological pattern of reorganization seen in animals [6]. Specifically, there was a silent zone of BOLD activity between IPZ and LPZ, whereas the electrophysiological response seen in animals usually spreads continuously from the IPZ to the LPZ, showing no gap.

Masuda et al. tried to solve the inconsistencies by using an fMRI paradigm comprising tasks of varying complexity (passive viewing, passive judgement and OBT) in four MD patients while presenting visual stimuli of equally varying complexity (reversing checkerboards, drifting contrast patterns, intact and scrambled faces) at their perifoveal PRL (Fig. 4c) [24]. Strikingly, during OBT only, the PRL cortical projection zone (IPZ) activation clearly extended into the LPZ of V1 in three of the four patients, regardless of the visual stimulus presented. Further work by Liu et al. and Masuda et al. has replicated these findings in MD and retinitis pigmentosa patients (Fig. 4d), respectively [5, 26]. Taken together, it was then suggested that in patients with acquired retinal disease, the loss of retinal input conveyed by feedforward circuits to V1 could functionally uncover the feedback circuits connec ting higher-order cortical areas to V1, specifically during the performance of more complex tasks (e.g. OBT), resulting in V1 LPZ activity [3, 24]. Indeed, it has been shown that taskrelated V1 foveal activity is modulated by attention and visual-mental imagery even in normal individuals, and such modulation has in fact been reported under peripheral (nonfoveal) visual stimulation [38-40]. Moreover, if LPZ V1 activity was already seen during passive viewing paradigms (e.g. checkerboard pattern), just like in Baseler's study on congenital retinal disease, this pattern would favour the presence of a stronger degree of plasticity, possibly reflecting structural changes (reorganization) within V1 [9, 24]. Under this theory, it still becomes difficult to explain Baker et al.'s subsequent findings, who demonstrated V1 LPZ BOLD activity in two MD patients from their original study during passive viewing of flickering checkerboards presented at their PRL (Fig. 4e) [21]. Recently, Baseler et al. have revisited this issue in the single largest fMRI study performed to date. Using conventional retinotopic mapping analysis, the authors additionally performed population receptive field (pRF) analysis and quantitative assessment of the retinotopic maps in a group of $12 \mathrm{MD}$ patients. pRF methods are more precise than conventional retinotopic mapping and match more closely electrophysiological measurements. The former methods estimate not only a visual field map but also take into account other neuronal population properties, including the range of visual 


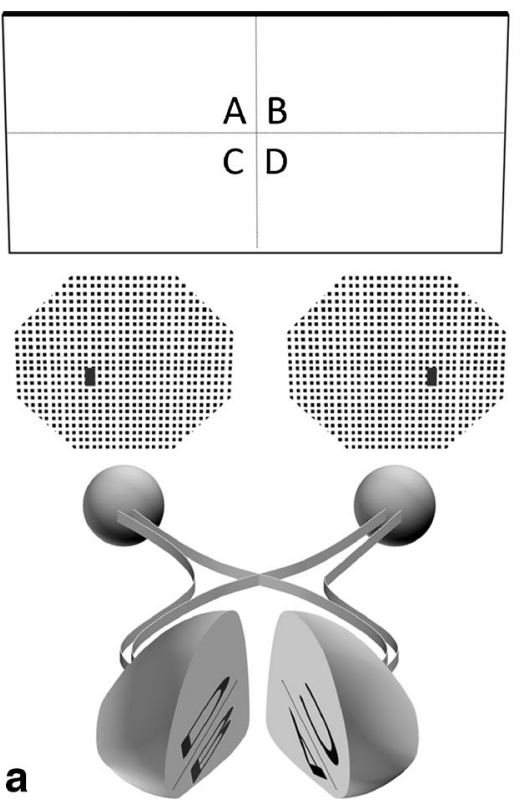

Fig. 3 Schematic representation of the retinotopic representation of the primary visual cortex (V1). a Nearby locations in the visual field are represented at nearby locations in V1 (topographical mapping). Peripheral vision is processed in anterior V1, whereas central (foveal) vision is processed by a disproportionally larger area in posterior V1 (occipital pole) (cortical magnification) $[35,36]$. b In a patient with rod achromacy, because the primary visual cortex (V1) is deprived of its

field locations which stimulate the neuronal population within a voxel [41]. A central scotoma was simulated in a group of 12 controls by placing a static disc at mean luminance grey at the centre of the visual stimulus throughout the scan [10]. The results were consistent with the absence of significant reorganization or remapping in the V1 LPZ in MD patients (Fig. 4b). Specifically, both patients and controls with simulated central scotomas showed no relevant BOLD activity at the occipital pole (LPZ). Importantly, in about $5 \%$ of voxels, both groups showed neuronal pRF changes in the LPZ. The authors reasoned that this ectopic activity at LPZ, strikingly present in controls immediately after inducing an artificial scotoma, possibly arised from large and/or displaced receptive fields, originated by dynamic changes occurring either in V1 intrinsic horizontal connections or in feedback pathways to V1. Hence, the presence of BOLD signal in the deprived visual cortex described in some reports, which has been taken by some groups as an fMRI evidence of long-term cortical structural changes, may in fact represent a form of short-term cortical adaptation, as recently shown by Barton and Brewer in normal individuals with simulated central scotomas [42••]. It is likely that this form of adaptation will then be adjusted across time by feedback signals from higher-level visual areas, in order to optimise vision $[23 \bullet \bullet$.

Many of the above studies tested perifoveal stimulation at the PRL location in MD patients (or a matched location in controls). Dilks et al. asked whether V1 LPZ BOLD signal

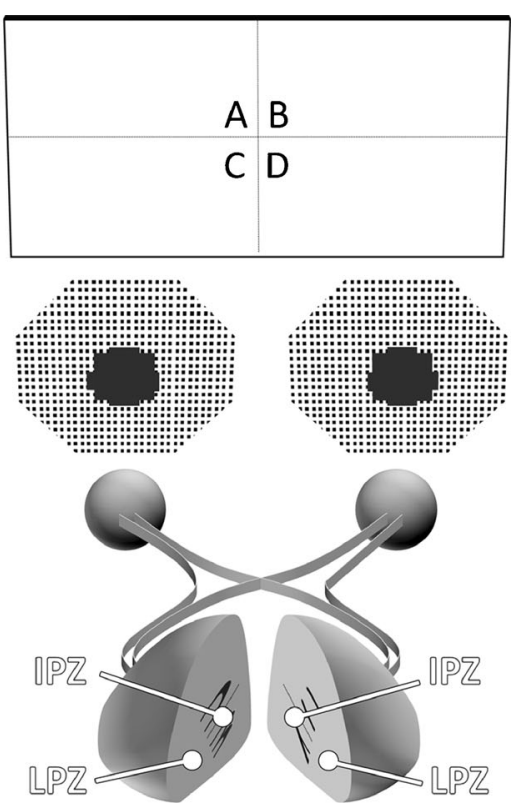

normal retinal input (represented by bilateral central scotomas), a circumscribed cortical area to which the lesioned retinal area projects can be defined (lesion projection zone (LPZ); in the example, posterior V1 or occipital pole, in both hemispheres). The spared retina, on the other hand, maintains its normal input to the corresponding V1 area (intact projection zone (IPZ); in the example, the anterior visual cortex). For further details, see Fig. 1 legend

was influenced by visual stimuli peripheral location: PRL versus non-PRL equally eccentric locations. Interestingly, they found robust activation at IPZ and LPZ to stimuli presented at either peripheral location (PRL and non-PRL) [27]. Yet, Schumacker et al. found opposite results, by showing BOLD signals at the IPZ and LPZ, only when the visual stimulus was presented at their PRL [28]. Liu et al. did report greater cortical activation only during PRL visual stimulation, but only at IPZ and not at the foveal confluence [5]. Therefore, it is currently unclear if there is a functional relationship between PRL use and V1 reorganization. Still, these apparently discordant results can eventually be reconciled. The PRL location in late onset MD patients is thought to be more influenced by cortical reorganization, since its location is usually within $2^{\circ}$ of the scotoma border, and the reorganization process seems to be particularly active at the scotoma border cortical representation. In contrast, in early onset MD patients, PRL location may drive more independently from cortical reorganization and is probably more linked to experience/training, since its location is usually at least $2^{\circ}$ from the scotoma border [20, 43]. Indeed, in Schumacker's study, five out of six patients had late onset MD, while in Dilks's study, both patients had early onset MD $[27,28]$. Results of the Liu's study are more difficult to interpret, since there was no evidence of visual cortical plasticity. Foveal vision sparing seems to preclude V1 plasticity in MD patients (Fig. 4f). This has been confirmed in three studies [11, $21,24]$. Probably, the visual field defect is not large enough to 


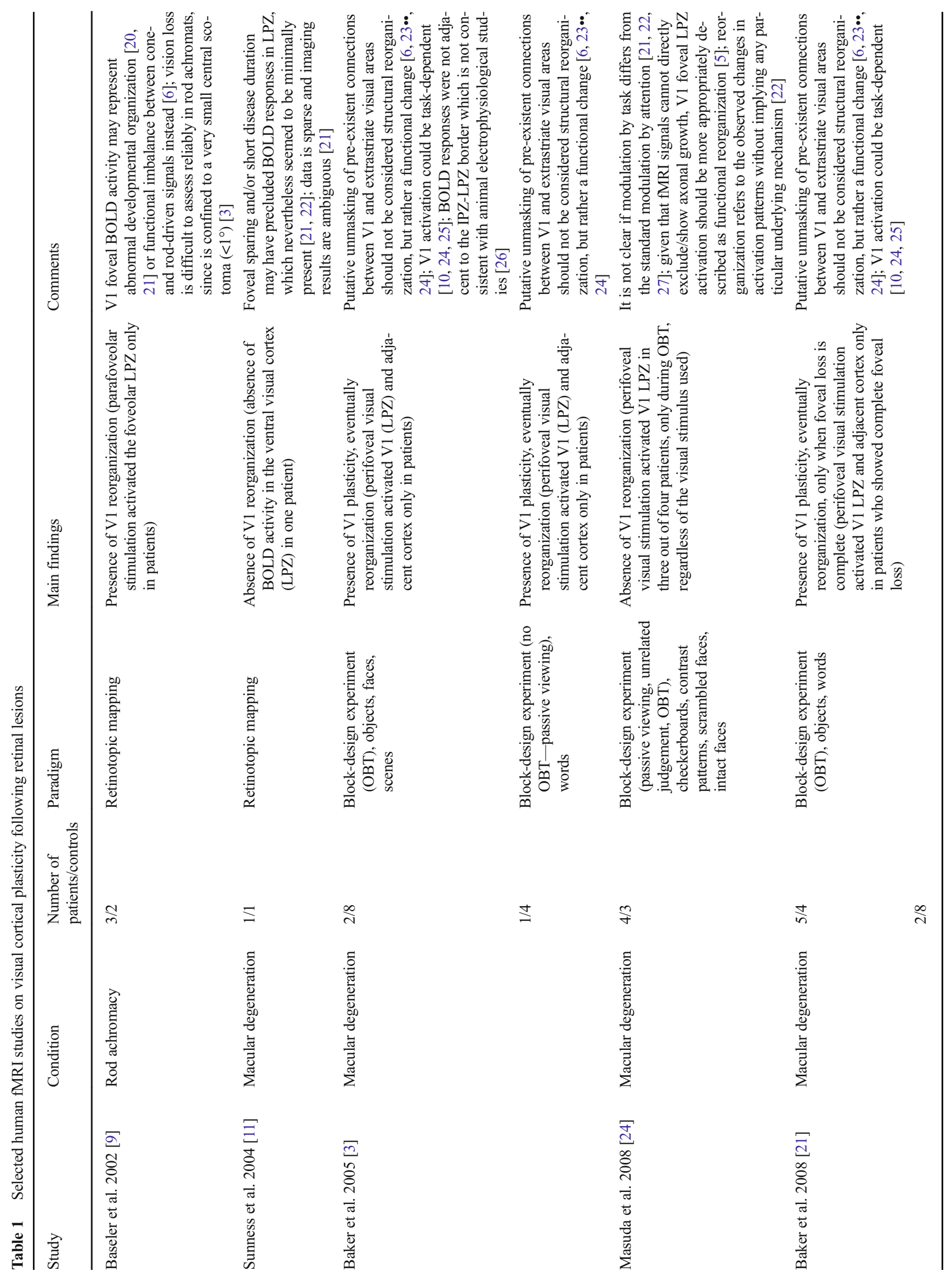




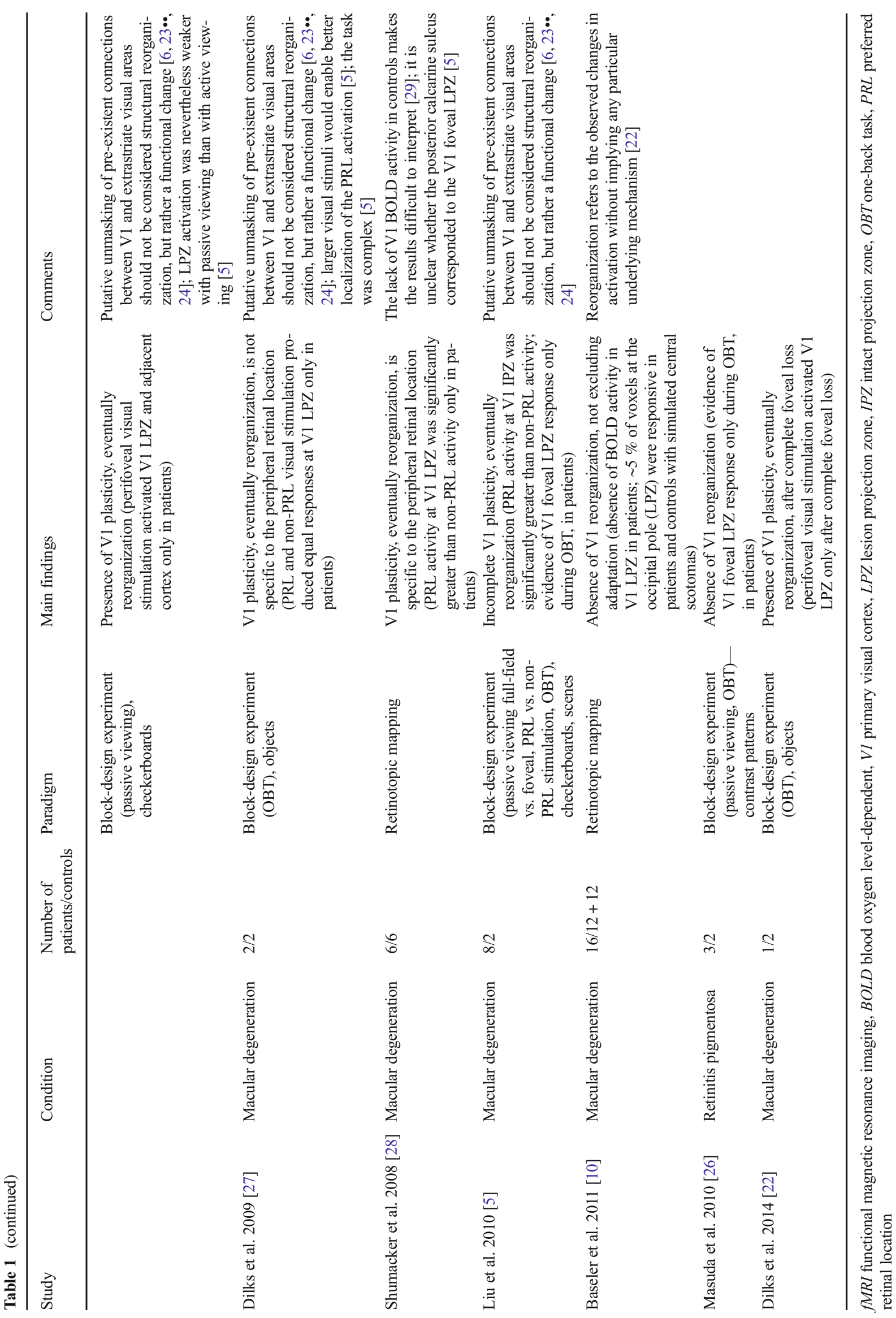




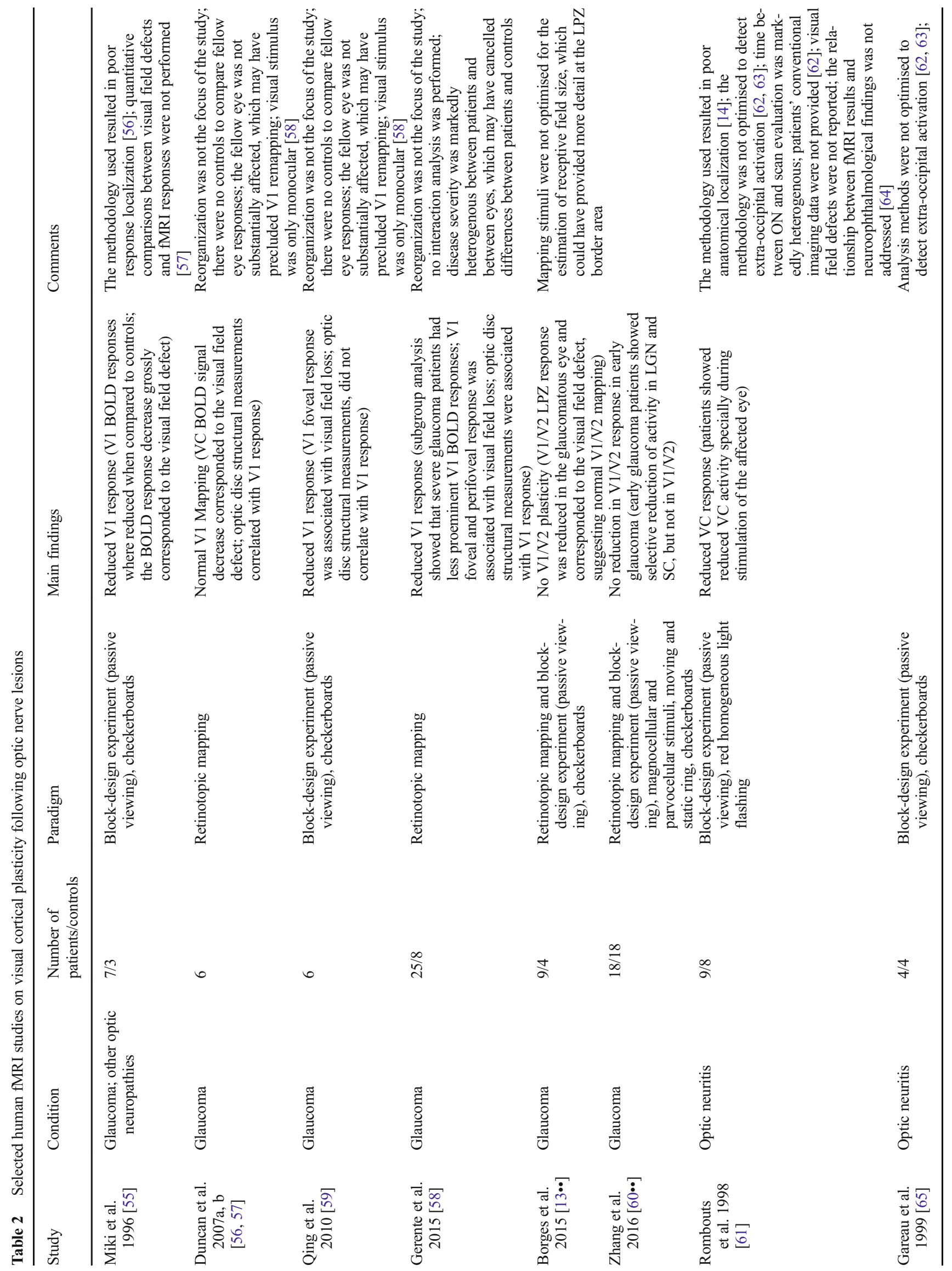




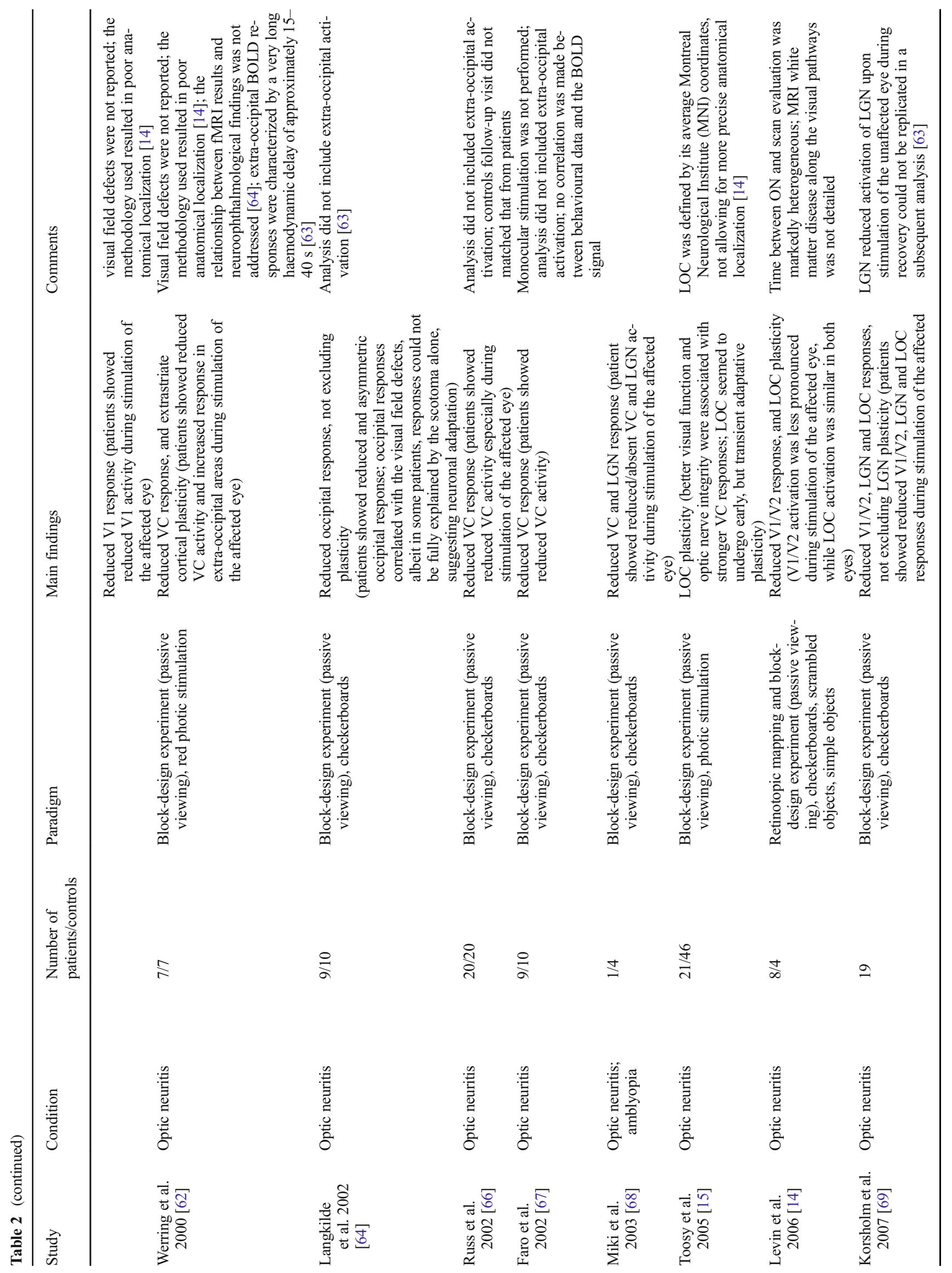




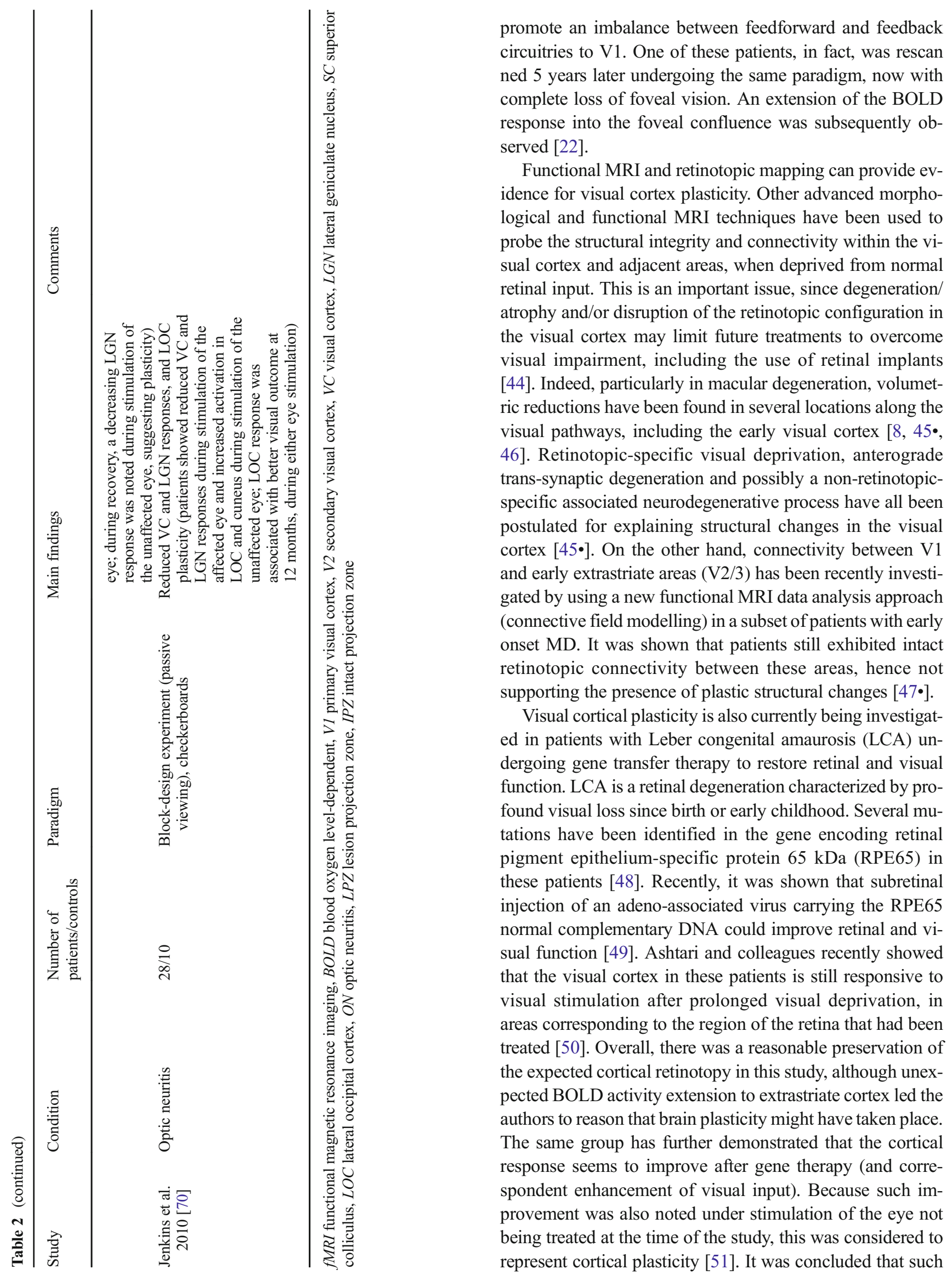


Fig. 5 fMRI evidence for primary visual cortex (V1) plasticity following optic nerve lesions. In patients with unilateral glaucoma, there is a

retinotopically localized reduction of activation in V1 during stimulation of the affected eye (right) when compared to stimulation of the fellow eye (left) $[13 \bullet \bullet]$. In the example depicted, monocular stimulation is alternated, by covering one eye at a time. For further details, see Fig. 1 legend
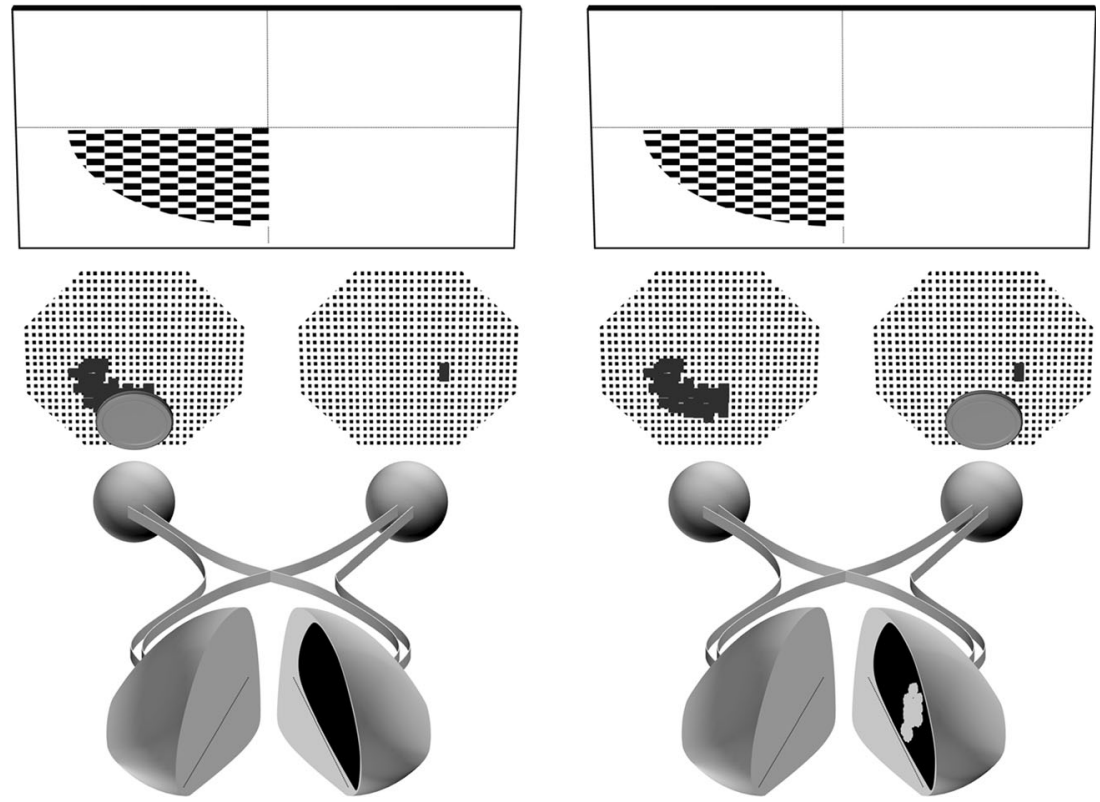

plasticity is possibly related to structural remodelling of the V1 and geniculostriate fibres [52]. The lack of comparison with fMRI assessment before initiating gene transfer therapy in the majority of these patients precludes additional conclusions, particularly when it is known that visual cortex BOLD response in untreated LCA patients can be normally activated if sufficient light stimulation is given [53]. In one other report, there was no evidence of visual cortex plasticity after gene therapy. Importantly, both patients had foveal sparing, which may have precluded plasticity [54•].

\section{Optic Nerve Lesions}

Human fMRI studies investigating the effects of optic neuropathy on the visual cortex are scarce, and most of them do not probe cortical reorganization directly, often lacking precise retinotopic mapping (Table 2).

Glaucoma is a chronic optic neuropathy with evidence of retinal ganglion cell loss, leading to cupping and atrophy of the optic disc and corresponding visual field defects prog ressing from peripheral to central areas. Recent evidence has demonstrated that glaucoma neurodegenerative changes also extend to the visual cortex, probably mediated transsynaptically [71]. Importantly, additional central nervous system involvement in frontal, temporal and parietal areas has been evidenced [71]. In fact, glaucoma patients seem to show lower cognitive scores than controls, albeit this needs to be further investigated by using thorough cognitive testing in a large number of patients [72]. In early work, Miki et al. showed that the BOLD decrease in V1 grossly corresponded to the visual deficits in three patients with glaucoma [55]. Contemporary work, using more sophisticated mapping techniques, has replicated these findings, by demonstrating a decrease of V1 LPZ BOLD activity, and thus suggesting absence of V1 reorganization or remapping (Fig. 5) [13••, 56, 57]. Since many of these studies included patients with unilateral glaucoma, the fact that one eye was largely unaffected may have precluded V1 plasticity. Qing et al. reported that foveal V1 BOLD response was less prominent in glauco matous patients, albeit their visual field deficit was peripheral [59]. A subclinical decrease of retinal ganglion cells may have led to reduced retinal input to foveal representation in V1. Interestingly, in the above studies, fMRI response seems to correlate with the structural measurements of the optic disc and visual field loss [56-58]. Taken together, it has been suggested that the reduction of V1 BOLD response in glaucoma patients probably reflects trans-synaptic degeneration in V1 and subsequent atrophy [71]. Interestingly, anterograde trans-synaptic degeneration seems to selectively affect the subcortical visual nuclei first, before reaching V1. Zhang et al. supported this theory by showing a normal V1 BOLD response in patients with early stage glaucoma, in sharp contrast with the reduced activity at the subcortical visual nuclei (i.e. lateral geniculate nucleus and superior colliculus) [60••]. Indeed, several structural imaging studies have provided a strong line of evidence for V1 and V2 atrophy in glaucoma patients [8, 73-76]. Equally important is the finding of volumetric increase in visual and non-visual areas distant from V1 and V2, including the cuneus, inferior occipital and temporal gyrus, and superior parietal and angular gyrus, which may indicate compensatory cortical plasticity, especially in early disease [73-75]. Further investigations are needed to probe these results (i.e. lack of $\mathrm{V} 1$ plasticity, normal V1 BOLD response in early glaucoma, plasticity in higher-order visual areas), especially in patients with bilateral glaucoma, the most common form of the disease, since the presence of normal 
visual function in one eye is thought to preclude V1 plasticity. Importantly, future fMRI studies on glaucoma should use a control group comprising patients with optic neuropathies other than glaucoma in whom visual cortex appears to be intact, in order to better interpret the apparent loss of V1 BOLD signal in glaucoma.

Optic neuritis $(\mathrm{ON})$ is an acquired demyelinating optic neuropathy frequently associated with multiple sclerosis, which classically presents with transient unilateral loss of visual acuity and colour vision, usually with a central scotoma. Clinical recovery is the rule, though persistence of paraclinical abnormalities (e.g. conduction delay in visual evoked potentials (VEP)) is common residual deficit [62]. This raises the possibility that visual cortical plasticity in V1 or higher-order visual areas may contribute to the behavioural recovery process. As in glaucoma however, there is a suggestion that abnormal reduced responses in the early visual cortex seem to be circumscribed to the retinotopically corresponding visually deprived areas, thus supporting lack of plasticity at V1 [14, 64]. Evidence is nevertheless weak, since retinotopic mapping techniques have not been used consistently. Instead, the presence of intact and/or increased activation in higher-order visual areas (e.g. lateral occipital cortex (LOC)) may in fact represent cortical plasticity contributing to the recovery process (see below) [15]. In ON studies, and unlike the terminology chosen for this paper, the term reorganization is often used to describe fMRI changes thought to reflect functional changes in neuronal function and their interactions (and not necessarily remapping), which ultimately contribute to maintain clinical function 'adaptative reorganization' or not 'non-adaptative reorganization' [15]. Rombouts et al. showed for the first time in ON patients that monocular visual stimulation, especially over of the affected eye, resulted in smaller BOLD activity in the early visual cortex, advocating that these results were due to substantial reduction of the visual input [61]. Subsequent studies have reproduced these findings in the early visual cortex, and some additionally reported increased BOLD activity in several higher-order extrastriate areas [62, 64-66, 68]. LOC, however, has been the extrastriate area that most consistently shows increased BOLD activity during both the acute and recovery phase of ON (but see Korsholm et al. 2007) $[14,15,69,70]$. In fact, the greater LOC response in the acute phase, the better is the visual outcome at 1 year, after accounting for other markers of tissue damage [70]. Increased BOLD activity in extra striate areas is currently regarded as a form of neuro plasticity, thought to represent a functional suppression of the abnormal input from the affected eye and/or structural synaptic reorganization or dendritic arborisation $[62,70]$. Early visual cortex (V1/V2) BOLD responses on the other hand, usually decreased during stimulation of the (more) affected eye, seem to result from a dynamic balance between feedforward and feedback signals to V1, coming from retinogeniculate fibres and higher-order extrastriate areas, respectively [14]. Still, it is necessary that future investigations using retinotopic mapping techniques investigate in detail early visual cortex responses in $\mathrm{ON}$ and probe earlier assumptions suggesting preservation of retinotopy in early visual cortex [64]. The possibility of LGN plasticity in $\mathrm{ON}$ is so far equivocal [69, 70]. Nota bly, in the majority of these studies, functional and structural markers of optic nerve integrity and visual function correlated with striate and/or extrastriate BOLD activity [62, 64-66, 69, 70]. If indeed higher-order visual cortex plays a role in $\mathrm{ON}$ recovery, it seems to be limited to static visual functions, since motion-related extrastriate cortical areas demonstrate sustained reduced BOLD activity following $\mathrm{ON}$ and correlate with the performance of tasks that require motion perception [77]. Additionally, structural imaging studies have corroborated the lack of neuroplasticity in the early visual cortex (V1/V2) by demonstrating local atrophy, presumingly caused by transsynapic anterograde degeneration following $\mathrm{ON}$ and/or the development of silent lesions in the optic radiations [78]. Recently, Raz et al. (2013) has proposed a very interesting theory of reorganization in ON. Since the fellow (presumingly unaffected) eye seems to evidence a VEP delay in time-to-peak which is not related to subclinical demyelination, the authors suggest that such delay may reflect an adaptive plastic process, eventually mediated by the visual cortex and/or LGN to compensate for the reduced retinal inputs arriving from the affected eye. Thus, instead of spatial reorganization, this could represent temporal reorganization, which provides a subnormal temporal synchronization between the eyes in order to enable binocular vision [79]. This data may help to contextualize Korsholm et al.'s work showing LGN activity changes following ON during stimulation of the fellow eye [69].

Unlike ON, anterior ischemic optic neuropathy (AION), resulting from acute infarction of the optic nerve head, has not been studied in detail with fMRI. The visual prognosis is considerably worse than in $\mathrm{ON}$, although around $30 \%$ of patients may improve visual acuity by several lines over 2 years [80]. Aguirregomozcorta et al. (2011) showed reduced activation in visual areas during visual stimulation of the affected eye, following an episode of AION. These features persisted over 6 months, which is consistent with the poor visual recovery documented in their series. Impor tantly, fellow eye stimulation in patients generated greater activation in extrastriate cortex than in controls, which was considered a form of neuroplasticity [81].

While most of research detailed here has concerned the presence of cortical plasticity among patients with established visual field defects, it should be noted that in certain diseases, 
cortical plastic changes probably begin even before a clinically measurable visual insult occurs, in the pre-symptomatic stage. One such example is Leber hereditary optic neuropathy (LHON), a mitochondrial inherited genetic disorder, which ultimately results in severe bilateral centrocecal scotomas in young adults. Carriers often show occult or subclinical abnormalities such as the presence of retinal nerve fibre layer (RNFL) swelling, before developing severe absolute central scotomas [82]. Work from our lab has measured the cortical thickness of V1, V2 and V3 areas (pre-retinotopically mapped) in 15 LHON carriers. Notably, extrastriate V2 and $\mathrm{V} 3$ areas showed increased cortical thickness when compared to controls [19]. Furthermore, we found that the peripheral retinotopic portions of $\mathrm{V} 2 / \mathrm{V} 3$ regions, in particular, were strongly correlated with RNFL swelling and associated with the relative paracentral visual field defects found in the majority of these patients. We reasoned that early retinal and visual field changes have probably triggered extrastriate cortical plasticity without disrupting retinotopic maps, similarly to what has been shown in glaucoma (see above) [83].

\section{Corneal, Quiasmal and Optic Radiation Lesions}

A few case reports have examined the visual cortex response following lesions in the visual pathways in locations other than the retina and optic nerve. Huber et al. (2015) among others reported a patient who had monocular vision restored in adulthood after becoming blind due to bilateral corneal trauma at the age of 3 . Since surgery, there was little recovery of vision and functional and structural imaging showed marked decrease in BOLD activity in striate and extrastriate cortices and microstructural abnormalities in the retroge niculate pathways $[84 \cdot, 85]$. Visual deprivation at an early age seems to have arrested the development of visual neurons with small foveal receptive fields, which are fundamental for object recognition [86]. In acquired (intrinsic and extrinsic) chiasmal damage in adulthood, it has been shown that visual cortical areas receiving retinal input from the crossing nasalretinal fibres became deprived and are not activated during visual stimulation $[87,88]$. The recovery documented on visual field perimetry in these cases nicely correlates with the return of BOLD signal in previously visually deprived areas [87]. No evidence of plasticity was found in these cases. Contrasting with the above-mentioned reports, V1 plasticity (possibly reorganization) has been claimed in a stroke patient showing partial damage of the right inferior optic radiations and a corresponding left upper visual field defect. Retinotopic mapping revealed an expansion of BOLD activity from the cortical representation of left lower visual field IPZ into the left upper visual field LPZ. Interestingly, this 'distortion' of the visual field map was accompanied by a similar subjective perceptual distortion (a square was perceived as a rectangle extending vertically) [32].

\section{Conclusions}

In congenital bilateral retinal diseases, primary visual cortex seems to undergo extensive remapping, allocating more space to visually deprived regions. In contrast, in acquired bilateral retinal diseases, structural plasticity seems to be limited, and robust fMRI evidence for reorganization in the adult visual cortex is lacking. In macular degeneration, task-dependent re-weighting of feedback signals from extrastriate areas seems a more plausible explanation for the presence of BOLD signal in the foveal representation than cortical reorganization. In optic nerve diseases such as glaucoma, emerging evidence also suggests that normal mapping is preserved; at least in primary visual cortex, reorganization seems to be absent. Parti cularly, in unilateral glaucoma, visual cortex plasticity may be precluded by the presence of normal visual function in the fellow eye. Yet, an increasing number of functional and structural imaging studies on glaucoma and other optic neuropathies such as optic neuritis have shown that plasticity is probably taking place beyond the primary visual cortex at higher-order visual areas. The exact role of these areas and their impact on clinical status needs to be probed further. The presence of transneuronal degeneration in the visual cortex may pose constraints on improving vision in patients with eye diseases, since it may interfere with restorative treatments. Longitudinal studies are crucial to trace its progression and provide information about the best timing to prevent it. More research using standard retinotopic procedures is needed to establish whether visual cortex fully retains its retinotopic organization following optic nerve diseases.

\section{Compliance with Ethical Standards}

Conflict of Interest João Lemos, Daniela Pereira and Miguel CasteloBranco declare that they have no conflict of interest.

Human and Animal Rights and Informed Consent This article does not contain any studies with human or animal subjects performed by any of the authors.

\section{References}

Papers of particular interest, published recently, have been highlighted as:

- Of importance

• Of major importance

1. Gilbert CD, Li W. Adult visual cortical plasticity. Neuron. 2012;75: 250-64.

2. Darian-Smith C, Gilbert CD. Axonal sprouting accompanies functional reorganization in adult cat striate cortex. Nature. 1994;368: $737-40$. 
3. Baker CI, Peli E, Knouf N, Kanwisher NG. Reorganization of visual processing in macular degeneration. J Neurosci. 2005;25:614-8.

4. Karmarkar UR, Dan Y. Experience-dependent plasticity in adult visual cortex. Neuron. 2006;52:577-85.

5. Liu T, Cheung S-H, Schuchard RA, Glielmi CB, Hu X, He S, et al. Incomplete cortical reorganization in macular degeneration. Invest Ophthalmol Vis Sci. 2010;51:6826-34.

6. Wandell BA, Smirnakis SM. Plasticity and stability of visual field maps in adult primary visual cortex. Nat Rev Neurosci. 2009;10: 873-84.

7. Abe H, McManus JNJ, Ramalingam N, Li W, Marik SA, Meyer zum Alten Borgloh S, et al. Adult cortical plasticity studied with chronically implanted electrode arrays. J Neurosci. 2015;35:277890.

8. Boucard CC, Hernowo AT, Maguire RP, Jansonius NM, Roerdink JBTM, Hooymans JMM, et al. Changes in cortical grey matter density associated with long-standing retinal visual field defects. Brain. 2009;132:1898-906.

9. Baseler HA, Brewer AA, Sharpe LT, Morland AB, Jägle H, Wandell BA. Reorganization of human cortical maps caused by inherited photoreceptor abnormalities. Nat Neurosci. 2002;5:36470 .

10. Baseler HA, Gouws A, Haak KV, Racey C, Crossland MD, Tufail A, et al. Large-scale remapping of visual cortex is absent in adult humans with macular degeneration. Nat Neurosci. 2011;14:649-55.

11. Sunness JS, Liu T, Yantis S. Retinotopic mapping of the visual cortex using functional magnetic resonance imaging in a patient with central scotomas from atrophic macular degeneration. Ophthalmology. 2004;111:1595-8.

12. Calford MB, Chino YM, Das A, Eysel UT, Gilbert CD, Heinen SJ, et al. Neuroscience: rewiring the adult brain. Nature. 2005;438:E3. discussion E3-4.

13.•• Borges VM, Danesh-Meyer HV, Black JM, Thompson B. Functional effects of unilateral open-angle glaucoma on the primary and extrastriate visual cortex. J Vis. 2015;15:9. The authors in this study show a retinotopically localized reduction of activation in early visual cortex of glaucoma patients, during stimulation of the affected eye. Importantly, they employ rigorous mapping techniques to support their findings.

14. Levin N, Orlov T, Dotan S, Zohary E. Normal and abnormal fMRI activation patterns in the visual cortex after recovery from optic neuritis. Neuroimage. 2006;33:1161-8.

15. Toosy AT, Hickman SJ, Miszkiel KA, Jones SJ, Plant GT, Altmann DR, et al. Adaptive cortical plasticity in higher visual areas after acute optic neuritis. Ann Neurol. 2005;57:622-33.

16. Sereno MI, Dale AM, Reppas JB, Kwong KK, Belliveau JW, Brady $\mathrm{TJ}$, et al. Borders of multiple visual areas in humans revealed by functional magnetic resonance imaging. Science. 1995;268:88993.

17. DeYoe EA, Carman GJ, Bandettini P, Glickman S, Wieser J, Cox R, et al. Mapping striate and extrastriate visual areas in human cerebral cortex. Proc Natl Acad Sci U S A. 1996;93:2382-6.

18. Engel S, Glover GH, Wandell BA. Retinotopic organization in human visual cortex and the spatial precision of functional MRI. Cereb Cortex. 1997;7:181-92.

19. d'Almeida OC, Mateus C, Reis A, Grazina MM, Castelo-Branco M. Long term cortical plasticity in visual retinotopic areas in humans with silent retinal ganglion cell loss. Neuroimage. 2013;81:222-30.

20. Cheung S-H, Legge GE. Functional and cortical adaptations to central vision loss. Vis Neurosci. 2005;22:187-201.

21. Baker CI, Dilks DD, Peli E, Kanwisher N. Reorganization of visual processing in macular degeneration: replication and clues about the role of foveal loss. Vision Res. 2008;48:1910-9.
22. Dilks DD, Julian JB, Peli E, Kanwisher N. Reorganization of visual processing in age-related macular degeneration depends on foveal loss. Optom Vis Sci. 2014;91:e199-206.

23.• Haak KV, Morland AB, Engel SA. Plasticity, and its limits, in adult human primary visual cortex. Multisens Res. 2015;28:297-307.

This is an excellent review in which the authors summarize the literature on cortical visual plasticity and further proposed a cost theory to support the lack of reorganization in the primary visual cortex.

24. Masuda Y, Dumoulin SO, Nakadomari S, Wandell BA. V1 projection zone signals in human macular degeneration depend on task, not stimulus. Cereb Cortex. 2008;18:2483-93.

25. Haak KV, Langers DRM, Renken R, van Dijk P, Borgstein J, Cornelissen FW. Abnormal visual field maps in human cortex: a mini-review and a case report. Cortex. 2014;56:14-25.

26. Masuda Y, Horiguchi H, Dumoulin SO, Furuta A, Miyauchi S, Nakadomari S, et al. Task-dependent V1 responses in human retinitis pigmentosa. Invest Ophthalmol Vis Sci. 2010;51:5356-64.

27. Dilks DD, Baker CI, Peli E, Kanwisher N. Reorganization of visual processing in macular degeneration is not specific to the "preferred retinal locus". J Neurosci. 2009;29:2768-73.

28. Schumacher EH, Jacko JA, Primo SA, Main KL, Moloney KP, Kinzel EN, et al. Reorganization of visual processing is related to eccentric viewing in patients with macular degeneration. Restor Neurol Neurosci. 2008;26:391-402.

29. Baseler HA, Gouws A, Morland AB. The organization of the visual cortex in patients with scotomata resulting from lesions of the central retina. Neuro-Ophthalmology. 2009;33:149-57.

30. Darian-Smith C, Gilbert CD. Topographic reorganization in the striate cortex of the adult cat and monkey is cortically mediated. J Neurosci. 1995;15:1631-47.

31. Heinen SJ, Skavenski AA. Recovery of visual responses in foveal V1 neurons following bilateral foveal lesions in adult monkey. Exp Brain Res. 1991;83:670-4.

32. Dilks DD, Serences JT, Rosenau BJ, Yantis S, McCloskey M. Human adult cortical reorganization and consequent visual distortion. J Neurosci. 2007;27:9585-94.

33. Giannikopoulos DV, Eysel UT. Dynamics and specificity of cortical map reorganization after retinal lesions. Proc Natl Acad Sci U S A. 2006;103:10805-10.

34. Smirnakis SM, Brewer AA, Schmid MC, Tolias AS, Schüz A, Augath $\mathrm{M}$, et al. Lack of long-term cortical reorganization after macaque retinal lesions. Nature. 2005;435:300-7.

35. Horton JC, Hoyt WF. The representation of the visual field in human striate cortex. A revision of the classic Holmes map. Arch Ophthalmol (Chicago Ill 1960). 1991;109:816-24.

36. Holmes G. Disturbances of vision by cerebral lesions. Br J Ophthalmol. 1918;2:353-84.

37. Das A, Gilbert CD. Long-range horizontal connections and their role in cortical reorganization revealed by optical recording of cat primary visual cortex. Nature. 1995;375:780-4.

38. Brefczynski JA, DeYoe EA. A physiological correlate of the "spotlight" of visual attention. Nat Neurosci. 1999;2:370-4.

39. Klein I, Paradis AL, Poline JB, Kosslyn SM, Le Bihan D. Transient activity in the human calcarine cortex during visual-mental imagery: an event-related fMRI study. J Cogn Neurosci. 2000;12 Suppl 2:15-23.

40. Williams MA, Baker CI, Op de Beeck HP, Mok Shim W, Dang S, Triantafyllou $\mathrm{C}$, et al. Feedback of visual object information to foveal retinotopic cortex. Nat Neurosci. 2008;11:1439-45.

41. Dumoulin SO, Wandell BA. Population receptive field estimates in human visual cortex. Neuroimage. 2008;39:647-60.

42.• Barton B, Brewer AA. fMRI of the rod scotoma elucidates cortical rod pathways and implications for lesion measurements. Proc Natl Acad Sci. 2015;112:5201-6. This study elegantly demonstrates that ectopic and/or size changes in neuronal receptive fields 
interacting with the visually deprived area in the primary visual cortex can be elicited in normal individuals with a central rod scotoma as a result of the normal short-term adaptation of the visual system and not due to reorganization.

43. Sunness JS, Applegate CA, Haselwood D, Rubin GS. Fixation patterns and reading rates in eyes with central scotomas from advanced atrophic age-related macular degeneration and Stargardt disease. Ophthalmology. 1996;103:1458-66.

44. Cunningham SI, Shi Y, Weiland JD, Falabella P, Olmos de Koo LC, Zacks DN, et al. Feasibility of structural and functional MRI acquisition with unpowered implants in Argus II retinal prosthesis patients: a case study. Transl Vis Sci Technol. 2015;4:6.

45. Prins D, Plank T, Baseler HA, Gouws AD, Beer A, Morland AB, et al. Surface-based analyses of anatomical properties of the visual cortex in macular degeneration. PLoS One. 2016;11, e0146684. This work shows that volumetric reductions in the visual cortex of patients with macular degeneration are marked in the early onset form, but subtle in the late onset form.

46. Hernowo AT, Prins D, Baseler HA, Plank T, Gouws AD, Hooymans JMM, et al. Morphometric analyses of the visual pathways in macular degeneration. Cortex. 2014;56:99-110.

47. Haak KV, Morland AB, Rubin GS, Cornelissen FW. Preserved retinotopic brain connectivity in macular degeneration. Ophthalmic Physiol Opt. 2016;36:335-43. This study investigates the functional connectivity between higher-order visual areas and the visually deprived primary visual cortex in macular degeneration patients. Retinotopic representation in primary visual cortex seems to be largely spared, despite the prolonged loss of visual input.

48. Marlhens F, Bareil C, Griffoin JM, et al. Mutations in RPE65 cause Leber's congenital amaurosis. Nat Genet. 1997;17:139-41.

49. Bainbridge JWB, Mehat MS, Sundaram V, et al. Long-term effect of gene therapy on Leber's congenital amaurosis. N Engl J Med. 2015;372:1887-97.

50. Ashtari M, Cyckowski LL, Monroe JF, et al. The human visual cortex responds to gene therapy-mediated recovery of retinal function. J Clin Invest. 2011;121:2160-8.

51. Bennett J, Ashtari M, Wellman J, et al. AAV2 gene therapy readministration in three adults with congenital blindness. Sci Transl Med. 2012;4:120ra15.

52. Ashtari M, Zhang H, Cook PA, et al. Plasticity of the human visual system after retinal gene therapy in patients with Leber's congenital amaurosis. Sci Transl Med. 2015;7:296ra110.

53. Aguirre GK, Komáromy AM, Cideciyan AV, et al. Canine and human visual cortex intact and responsive despite early retinal blindness from RPE65 mutation. PLoS Med. 2007;4, e230.

54. Cideciyan AV, Aguirre GK, Jacobson SG, Butt OH, Schwartz SB, Swider M, et al. Pseudo-fovea formation after gene therapy for RPE65-LCA. Invest Ophthalmol Vis Sci. 2015;56:526-37. In this study, it is shown that the activation in the visual cortex in Leber's congenital amaurosis patients undergoing gene therapy accurately corresponds to their visual field defects, both before and after therapy.

55. Miki A, Nakajima T, Takagi M, Shirakashi M, Abe H. Detection of visual dysfunction in optic atrophy by functional magnetic resonance imaging during monocular visual stimulation. Am J Ophthalmol. 1996;122:404-15.

56. Duncan RO, Sample PA, Weinreb RN, Bowd C, Zangwill LM. Retinotopic organization of primary visual cortex in glaucoma: a method for comparing cortical function with damage to the optic disk. Invest Ophthalmol Vis Sci. 2007;48:733-44.

57. Duncan RO, Sample PA, Weinreb RN, Bowd C, Zangwill LM. Retinotopic organization of primary visual cortex in glaucoma: comparing fMRI measurements of cortical function with visual field loss. Prog Retin Eye Res. 2007;26:38-56.

58. Gerente VM, Schor RR, Chaim KT, Mde Felix M, Ventura DF, Teixeira SH, et al. Evaluation of glaucomatous damage via functional magnetic resonance imaging, and correlations thereof with anatomical and psychophysical ocular findings. PLoS One. 2015;10, e0126362.

59. Qing G, Zhang S, Wang B, Wang N. Functional MRI signal changes in primary visual cortex corresponding to the central normal visual field of patients with primary open-angle glaucoma. Invest Ophthalmol Vis Sci. 2010;51:4627-34.

$60 . \bullet$ Zhang P, Wen W, Sun X, He S. Selective reduction of fMRI responses to transient achromatic stimuli in the magnocellular layers of the LGN and the superficial layer of the SC of early glaucoma patients. Hum Brain Mapp. 2016;37:558-69. This work suggests that in early glaucoma patients, neuronal degeneration might affect the lateral geniculate nucleus and superior colliculus before reaching the early visual cortex.

61. Rombouts SA, Lazeron RH, Scheltens P, Uitdehaag BM, Sprenger $\mathrm{M}$, Valk $\mathrm{J}$, et al. Visual activation patterns in patients with optic neuritis: an fMRI pilot study. Neurology. 1998;50:1896-9.

62. Werring DJ, Bullmore ET, Toosy AT, et al. Recovery from optic neuritis is associated with a change in the distribution of cerebral response to visual stimulation: a functional magnetic resonance imaging study. J Neurol Neurosurg Psychiatry. 2000;68:441-9.

63. Korsholm K, Madsen KH, Frederiksen JL, Rowe JB, Lund TE. Cortical neuroplasticity in patients recovering from acute optic neuritis. Neuroimage. 2008;42:836-44.

64. Langkilde AR, Frederiksen JL, Rostrup E, Larsson HBW. Functional MRI of the visual cortex and visual testing in patients with previous optic neuritis. Eur J Neurol. 2002;9:277-86.

65. Gareau PJ, Gati JS, Menon RS, Lee D, Rice G, Mitchell JR, et al. Reduced visual evoked responses in multiple sclerosis patients with optic neuritis: comparison of functional magnetic resonance imaging and visual evoked potentials. Mult Scler. 1999:5:161-4.

66. Russ MO, Cleff U, Lanfermann H, Schalnus R, Enzensberger W, Kleinschmidt A. Functional magnetic resonance imaging in acute unilateral optic neuritis. J Neuroimaging. 2002;12:339-50.

67. Faro SH, Mohamed FB, Tracy JI, Elfont RM, Pinus AB, Lublin FD, et al. Quantitative functional MR imaging of the visual cortex at 1.5 $\mathrm{T}$ as a function of luminance contrast in healthy volunteers and patients with multiple sclerosis. AJNR Am J Neuroradiol. 2002;23:59-65.

68. Miki A, Liu GT, Goldsmith ZG, Liu C-SJ, Haselgrove JC. Decreased activation of the lateral geniculate nucleus in a patient with anisometropic amblyopia demonstrated by functional magnetic resonance imaging. Ophthalmol J Int d'ophtalmologie Int J Ophthalmol Zeitschrift für Augenheilkd. 2003;217:365-9.

69. Korsholm K, Madsen KH, Frederiksen JL, et al. Recovery from optic neuritis: an ROI-based analysis of LGN and visual cortical areas. Brain. 2007;130:1244-53.

70. Jenkins TM, Toosy AT, Ciccarelli O, et al. Neuroplasticity predicts outcome of optic neuritis independent of tissue damage. Ann Neurol. 2010;67:99-113.

71. Chen WW, Wang N, Cai S, et al. Structural brain abnormalities in patients with primary open-angle glaucoma: a study with 3T MR imaging. Invest Ophthalmol Vis Sci. 2013;54:545-54.

72. Harrabi H, Kergoat M-J, Rousseau J, Boisjoly H, Schmaltz H, Moghadaszadeh S, et al. Age-related eye disease and cognitive function. Invest Ophthalmol Vis Sci. 2015;56:1217-21.

73. Zhang S, Wang B, Xie Y, Zhu S, Thomas R, Qing G, et al. Retinotopic changes in the gray matter volume and cerebral blood flow in the primary visual cortex of patients with primary openangle glaucoma. Invest Ophthalmol Vis Sci. 2015;56:6171-8.

74. Li C, Cai P, Shi L, et al. Voxel-based morphometry of the visualrelated cortex in primary open angle glaucoma. Curr Eye Res. 2012;37:794-802.

75. Williams AL, Lackey J, Wizov SS, et al. Evidence for widespread structural brain changes in glaucoma: a preliminary voxel-based MRI study. Invest Opthalmology Vis Sci. 2013;54:5880. 
76. Yu L, Yin X, Dai C, Liang M, Wei L, Li C, et al. Morphologic changes in the anterior and posterior subregions of $\mathrm{V} 1$ and $\mathrm{V} 2$ and the V5/MTp in patients with primary open-angle glaucoma. Brain Res. 2014;1588:135-43.

77. Raz N, Dotan S, Benoliel T, Chokron S, Ben-Hur T, Levin N. Sustained motion perception deficit following optic neuritis: behavioral and cortical evidence. Neurology. 2011;76:2103-11.

78. Balk LJ, Twisk JWR, Steenwijk MD, Daams M, Tewarie P, Killestein J, et al. A dam for retrograde axonal degeneration in multiple sclerosis? J Neurol Neurosurg Psychiatry. 2014;85:782-9.

79. Raz N, Chokron S, Ben-Hur T, Levin N. Temporal reorganization to overcome monocular demyelination. Neurology. 2013;81:702-9.

80. Ischemic Optic Neuropathy Decompression Trial Research Group. Ischemic optic neuropathy decompression trial: twenty-four-month update. Arch Ophthalmol (Chicago Ill 1960). 2000;118:793-8.

81. Aguirregomozcorta M, Mancini L, Jenkins TM, Hickman SJ, Ciccarelli O, Plant GT, et al. A longitudinal functional MRI study of non-arteritic anterior ischaemic optic neuropathy patients. $\mathrm{J}$ Neurol Neurosurg Psychiatry. 2011;82:905-13.

82. Sadun AA, Salomao SR, Berezovsky A, et al. Subclinical carriers and conversions in Leber hereditary optic neuropathy: a prospective psychophysical study. Trans Am Ophthalmol Soc. 2006;104:5161.

83. Mateus C, d'Almeida OC, Reis A, Silva E, Castelo-Branco M. Genetically induced impairment of retinal ganglion cells at the axonal level is linked to extrastriate cortical plasticity. Brain Struct Funct. 2016;221:1767-80.

84. Huber E, Webster JM, Brewer AA, MacLeod DIA, Wandell BA, Boynton GM, et al. A lack of experience-dependent plasticity after more than a decade of recovered sight. Psychol Sci. 2015;26:393-401. This is a case report supporting the absence of reorganization in the visual cortex in a patient with monocular vision restored after becoming blind due to corneal disease.

85. Raz N, Levin N. Cortical and white matter mapping in the visual system - more than meets the eye: on the importance of functional imaging to understand visual system pathologies. Front Integr Neurosci. 2014;8:68.

86. Levin N, Dumoulin SO, Winawer J, Dougherty RF, Wandell BA. Cortical maps and white matter tracts following long period of visual deprivation and retinal image restoration. Neuron. 2010;65: 21-31.

87. Raz N, Vaknin A, Chokron S, Ben-Hur T, Levin N. Functional MRI as a tool for assessing chiasmal visual defect in a patient with neuromyelitis optica. J Neurol Neurosurg Psychiatry. 2010;81:1174-5.

88. Nielsen K, Madsen KH, Frederiksen JL, Leffers AM, Lund TE. Functional magnetic resonance imaging corresponds to Humphrey perimetry in a patient with pituitary adenoma. Acta Ophthalmol Scand. 2006;84:267-8. 